\title{
Lecture and Workshop Review
}

\author{
The development of psychoanalysis in new areas, \\ revisiting the analytic attitude and Melanie's Klein's depressive position. \\ A review of Maria Teresa Savio Hooke's lecture and workshop.
}

\author{
Mark Thorpe \\ SENIOR LECTURER AT AUCKLAND UNIVERSITY OF TECHNOLOGY AND CLINICAL \\ PSYCHOLOGIST AT PSYCHOTHERAPY AT APOLLO
}

This article reviews a weekend of input by the distinguished Italian/Australian psychoanalyst Maria Teresa Savio Hooke.

The New Zealand Institute of Psychoanalytic Psychotherapy (NZIPP) had the honour of hosting Maria Teresa Savio Hooke in November 2016. The Auckland weekend was the culmination of the successful 2016 series of psychoanalytic seminars and workshops facilitated by the NZIPP as well as the hosting of the annual Psychoanalytic Psychotherapy Association of Australasia (PPAA) conference in Aotearoa New Zealand.

In June 2016, the NZIPP hosted the 36th Annual PPAA Conference in Auckland. The PPAA is a federated body composed of member organisations from most Australian States and New Zealand. The Auckland conference theme was Sexualities - Psychoanalytic (Re) thinking: Sex, Gender and Sexuality. Aotearoa New Zealand displayed strong presence at the conference with five NZIPP members presenting papers: "The choice of sex," by DrChantal Degril (2016); "Miss H's universe - from Awe to Eew! and back again," Judi Blumenfeld Hoadley (2016); "The Cowboy and the Damboo: A Quest for Potential Space and Psychological Life," Dr Mark Thorpe (2016); "Unveiling the Sect of the Phoenix," - Dr Gustavo Restivo (Restivo, 2016); and "Reflections on the development of love and sexual identity," - Dr Gloriana Bartoli (2016).

The NZIPP also presented a public series of psychoanalytic psychotherapy seminars and workshops in 2016. The series consisted of:

Three workshops presented by Dr. Leonardo Rodriguez, a Lacanian analyst from Melbourne: "Sexuality and Sexuation in the 21 Century;" "The Oedipus Complex Revisited: Freud, Levi-Strauss;" and "Lacan, Feminine Sexuality Today" (19 \& 20 February, 2016).The following papers were then presented: "The Logics of Sexuation" by Dr Gustavo Restivo (April, 2016): "The experience of supervising with a psychoanalytic sensibility in a behavioural world" by Dr Mark Thorpe (May) [see (Thorpe, 2015)]; "An interpretation

\footnotetext{
Thorpe, M.(2016).The development of psychoanalysis in new areas, revisiting the analytic attitude and Melanie's Klein's depressive position. [A review of Maria Teresa Savio Hooke's lecture and workshop.] Ata: Journal of Psychotherapy Aotearoa New Zealand, 20(2), 210-215. DOI:10.9791/ajpanz.2016.17 @ New Zealand Association of Psychotherapists Inc.
} 
of the Coen Brothers' movie True Grit through a psychoanalytic lens," by Blumenfeld Hoadley (July); and "Lost and Found, a 5-year-old struggle to find a home: An exploration of inner space and dimensionality through Meltzer's key concept of the claustrum," by Dr Peter Slater (published in this issue). The final NZIPP event in 2016 was a weekend of lectures and seminars presented by Maria Teresa Savio Hooke.

Maria Teresa Savio Hooke is a training and supervising analyst of the Australian Psychoanalytical Society, Chair of the International Psychoanalytic Association (IPA) International New Groups (ING) Committee. She was the Chair of the IPA Outreach and communications China Committee (2008-2013), the Co-Chair for Europe of the IPA Committee on Psychoanalytic Perspectives on Ageing (2007-2013), and the Chair of the Psychoanalysis and Psychoanalytic Psychotherapy Section of the Psychotherapy and Counselling Federation of Australia (PACFA). A selection of her pertinent writings includes: "Melanie Klein's depressive position" (Hooke, 1999); "Is Psychoanalysis still relevant?" (Hooke, 2000); "The tyranny of distance: The early history of the APSA" (Hooke, 2000); and "The geography of meanings: Psychoanalytic perspectives on place, space, and dislocation" (Hooke \& Akhtar, 2007). (For the history of the IPA, see http:// www.ipa.world/IPA/en/About/en/IPA1/ipa_history/history_of_the_ipa. aspx?hkey=fdo $\$ 11 d_{4}-6080-44$ bb-9098-f2adc8oofb23); and for a video of Maria Teresa discussing different psychoanalytic concepts such as projective identification, Klein's depressive position and empathy, the ageing psychoanalytic workforce etc., see http:// www.spiweb.it/video-2/661-psicoanalisti-nel-mondo/2734-maria-teresa-savio-hooke.)

The weekend started with a meeting with Maria Teresa Savio Hooke, in her role as Chair of the ING, and a small group of local therapists. The aim of the meeting was to facilitate the growth of psychoanalysis in Aotearoa New Zealand and to consider setting up an IPA Allied Centre, possibly linked to the NZIPP. Maria Teresa listened carefully to the different interests and needs of the attendees. The group discussed some of the history of psychoanalysis in Aotearoa New Zealand and it became clear that the only two previously registered psychoanalysts within the country were no longer members of the IPA. Maria Teresa has agreed to enter into an ongoing discussion with the group.

Maria Teresa then delivered a public lecture on the Friday night with the title "Psychoanalysis in new areas, new countries, new cultures." She focussed on the most recent spreading of psychoanalysis in new countries, outside of the traditional geographical context of Europe and North America such as the Asia Pacific, Russia, Eastern Europe (here the links are being re-established), some African countries and the Middle East. I was heartened to see the PowerPoint photograph of the South Africa psychanalytic group consisting of a few of my colleagues from Rhodes University and the Cape Town Psychoanalytic Group who had become psychoanalysts. The sponsor and training analyst was Professor Mark Solmes, currently Chair of Neuropsychology at the University of Cape Town and Groote Schuur Hospital, and President of the South African Psychoanalytical Association who I had known indirectly from school in Pretoria and the University of Witwatersrand. (See the fascinating 15 minute TedTalk on how Solmes, employing his psychoanalytic knowledge and the assistance of historians and archaeologists, tries to understand dialogue, and improve his relationship with the seven families who had lived on his family's wine farm for generations https://www.youtube. 
com/watch?v=pX17iQbLpQM. Although this event is set in South Africa, the themes may be of relevance to colonisation around the world including Aotearoa New Zealand).

Enough nostalgic free-associating and back to Maria Teresa's lecture on the process of setting up psychoanalytic trainings in new countries. She articulated the challenges and difficulties as well as the richness which she felt came from the cross-fertilisation, and from the encounters with other cultures and histories. Maria Teresa thought that one of the primary skills was to walk the fine line between over-adapting to the new culture, thereby losing the essence of the psychoanalytic worldview and sensibility, and rigidly adhering to the traditional Western oriented psychoanalysis, as a defence against relating to, and being influenced by, the different culture. She spoke poignantly of how the process has fuelled the need to review and re-think many of the fundamental psychoanalytic tenets. Many of the thoughts and discussions generated are pertinent to the application and development of psychoanalytic psychotherapy within Aotearoa New Zealand.

On Saturday, Maria Teresa presented a workshop called: "Revisiting the Analytic Attitude." She spoke in clear English, avoiding unnecessary psychoanalytic jargon. I had the sense that she had been teaching these concepts to a wide variety of students for the past decades. In the workshop she revisited the internal attitude of the psychoanalyst and the psychoanalytic psychotherapist in their patients and colleagues. She considered the historical context of the psychoanalytic attitude, how it began, gradually developed, and changed from the era of early Freud to contemporary psychoanalysis.

The next workshop presented by Maria Teresa was on "Melanie Klein's depressive position." She showed how the concept of the depressive position represented a momentous sea of change in psychoanalytic theory since Freud's postulations. She elucidated the importance of the depressive position for clinical work, the way we as clinicians view ourselves and in the history of countries coming to terms with massive trauma. Hooke said that Klein took depression out of the medicalised category of illness and placed experiences of loss, sadness, remorse, guilt and loneliness in the category of normal development that touches all of us.

Maria Teresa linked her presentation to the personal life experiences of Melanie Klein and showed how they influenced her development of the concept of the depressive position. She showed how the concept has changed over the years and how it is viewed by psychoanalysts today. She made it clear that Klein had intended the descriptions of the paranoid-schizoid and depressive positions as states of mind rather than developmental phases. In other words, our persecutory and depressive impulses fluctuate continually throughoutlife, depending on the interpersonal,psychic and environmental circumstances.

One aspect of Maria Teresa's exposition on the depressive position that I found particularly illuminating was that of reparation and the paranoid-schizoid equivalent, manic reparation. Klein, according to Maria Teresa, conceptualised reparation as a form of psychic re-building and renewed personal development following pain and loss. Reparation plays a fundamental role in the development, as one of the elements that facilitate working through the depressive position.

Klein states that love, and the capacity to bear guilt and pain, fuels reparation. Thus, acceptance of depressive pain is a pre-requisite for true reparation. Hooke explained that true reparation implies becoming aware of one's own aggression. Manic reparation on 
the other hand is characterised by a denial of the damage done, in phantasy and reality, and the importance of the lost object. The experience of guilt and pain is thereby avoided. An integrated mind is necessary to develop the capacity to bear pain and sustain guilt, without recourse to regression and use of paranoid-schizoid defences.

Manic defences, including manic reparation, are seen as a system of defences to protect the fragile ego from experiences of depressive anxiety, particularly guilt. They are characterised by the triad of control, triumph and contempt. The denial of dependence on the object and the importance of the object is continually denied, giving rise to experience of elation and mania.

Maria Teresa pointed out the obvious to an audience of psychotherapists; namely, that reparation is a primary motivator of becoming a healer or therapist. We repair our own damaged internal object by repairing the object of our client.

Can the concept of reparation, and its nemesis, manic reparation, be extended to the political realm? For example, it could be argued that the process of restorative justice undertaken after the abolition of South African apartheid in 1994, was a form of reparation. Similarly, it could be postulated that, notwithstanding the ongoing debate and differences in opinions, that Te Tiriti o Waitangi, and particularly the more recent Treaty of Waitangi claims and settlements process, could be conceptualised as the Crown's attempt at reparation by honouring the Treaty and attempting to redress Treaty grievances. Linking the personal and the social, perhaps the process of the Treaty settlements acts as a form of reparation for Pākehā New Zealanders towards their Mãori Treaty partners. Ideally, from a Kleinian perspective, the Pākehā population would identify, acknowledge and accept the ongoing damage unleashed upon Mãori, starting with the process of colonisation. Pākehā would become aware of their own feelings of aggression towards Māori and the damage done in phantasy and reality, and how this conflicts with their love, connection and dependency on Māori. Given sufficient ego strength, Pākehā would be able to sustain the resultant feelings of loss, sadness, remorse, guilt and loneliness. The result would then be a process of true reparation, a psychic rebuilding of self and a real, separate and respectful relationship with Māori. However, what would this look like if the pain and guilt was too great and the paranoid-schizoid defences and manic reparation predominated? According to Kleinian theory the relationship would become characterised by control, triumph and contempt, hidden below the surface of an apparently genuine attempt at reconciliation. This could manifest as a self-effacing, genuflecting, and overly adaptive stance Pākehā may manifest towards Māori. This stance would defensively cover the unacknowledged and unprocessed paranoid-schizoid fears. As the London based Jungian analyst, Andrew Samuels pointed out at the NZAP conference in Wellington many years ago, such defensive attitudes are rife in organisations whose primary task is to assist psychologically wounded people. Samuels also pointed out that the political power gradient at conferences such as ours was the reverse of that which occurred in the society at large. Clearly, our task as psychotherapists is to employ our own reparative capacities in the service of our client's and the society. I would argue that an equally important task is to monitor and be aware when our desire to heal and help falls under the defensive processes of manic reparation, thereby pushing all the difficult conflicts back into the unconscious and perhaps 
exacerbating the conflicts and potential damage.

Maria Teresa presented her material in an eloquent, articulate, interesting and sophisticated manner. She allowed a lot of time for dialectic discussion and her style facilitated the development of curiosity and reflection in the audience. Discussions with her continued in depth with those who attended the restaurant lunch and dinner. Being the only registered psychoanalyst, an eminent one at that, in the room and in the country (from Italy and Australia), Maria Teresa drew different transference responses from us. One of the questions, frequently asked in different forms and by different members of the audience, concerned the difference between psychodynamic psychotherapy and psychoanalysis. Maria Teresa, paused in what seemed like a reflective space, before answering each time. Most of her replies seemed to avoid the categorical rule bound differentiation, such as training and number of sessions per week, between psychoanalysis and psychoanalytic, and psychodynamic psychotherapy. The primary focus of her answers was rather on the degree of psychic depth reached in the therapy. Parallel to this line of questioning, was a form of audience comment or question, which tended to idealise psychoanalytic thinking, training and practice abroad and devaluing the quality of clinical work and general acceptance of psychoanalysis in Aotearoa New Zealand. Maria Teresa listened patiently to many of these comments and replied to some of them. The intensity of the audience comments increased as day progressed. Maria Teresa gradually started making mild group based interpretations about our comments. She firstly said, in different ways, that the difficulties we were complaining about, such as the resistance and opposition to psychoanalysis, were common in the rest of the "idealised" world. This brings to my mind a quote by Paul Schimmel, "It is suggested that hatred of psychoanalysis will be encountered in all parties (patient and analyst), consequent upon the inevitable presence within us of a hatred of, or resistance to, the delineation of psychic truth" (2010, p. 35). Marie Teresa later gently suggested that we were projecting our idealisations onto the Australian and other trainings abroad, and our devaluations onto the therapeutic scene in Aotearoa New Zealand. She later confessed to her own complementary idealizations of New Zealand being cleaner, greener and softer. These interventions seemed to allay some of our unconscious infantile anxieties about the loss of the bountiful breast, and the unique, perfect, uncontaminated exclusive relationship with the ideal mother/analyst, "Mother Theresa", about to abandon us and fly off to feed our greedy older siblings in Sydney. Possibly the group's anxieties were temporarily transformed from our paranoid-schizoid reactions of persecutory anxieties, employing the mechanisms of splitting, omnipotence, idealisation denial, to a depressive position where we perceived our temporary mother who, as a whole object, separate from our omnipotent control, and herself having a mix of good, bad and real aspects, had survived our attacks. A fitting, lived and felt demonstration of Maria Teresa's topic for the afternoon, Klein's depressive position.

Interested clinicians are referred to a few original references to Klein's depressive position (Klein, 1935, 1940; Segal, 1979). 


\section{MARK THORPE}

\section{References}

Blumfield Hoadley, J. (2016). Miss H's universe - from Awe to Eew! Paper presented at the meeting of the Psychoanalytic Psychotherapy Association of Australasia (PPAA) 2016 Annual Conference: Sexualities: Psychoanalytic (Re)Thinking: Sex, Gender, Sexuality, Auckland, New Zealand

Degril, C. (2016). The choice of sex. Paper presented at the meeting of the Psychoanalytic Psychotherapy Association of Australasia (PPAA ) 2016 Annual Conference: Sexualities: Psychoanalytic (Re)Thinking: Sex, Gender, Sexuality, Auckland, New Zealand.

Hooke, M. T. S. (1999). Melanie Klein's depressive position. Psychotherapy in Australia, 5(3), 38-44.

Hooke, M. T. S. (2000). Is psychoanalaysis still relevant? Psychotherapy in Australia, 7(1), 42-46.

Hooke, M. T. S., \& Akhtar, S. (2007). The geography of meanings: Psychoanalytic perspectives on place, space, land, and dislocation. London, United Kingdom: International Psychoanalytic Association.

Klein, M. (1935). A contribution to the psychogenesis of manic-depressive states. In Love, guilt and reparation. London, United Kingdom: Hogarth Press.

Klein, M. (1940). Mourning and its relation to manic-depressive states. In Love, guilt and reparation (pp. 145-174). London, United Kingdom: Hogarth Press.

Restivo, G. (2016). Unveiling the sect of the phoenix. Australasian Journal of Psychotherapy, $34(2), 31-45$.

Schimmel, P. (2010). Psychoanalysis: What it is and why it is hated. Psychoanalysis Downunder (10).

Segal, H. (1979). Klein. London, United Kingdom: Fontana.

Thorpe, M. R. (2015). Psychoanalytic sensibility in a behavioural world: Supervising intern counselling psychologists in Aotearoa New Zealand. In Z. G. Knight (Ed.), Psychoanalysis: perspectives, techniques and socio-psychological implications (pp. 31-50). New York, NY: Nova Science Publishers.

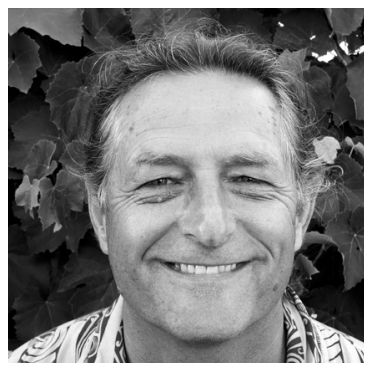

Dr Mark Thorpe is a senior lecturer at Auckland University of Technology and practices as a clinical psychologist at Psychotherapy at Apollo. He trained in a variety of therapeutic modalities and worked in private, governmental, and university settings in South Africa and Aotearoa New Zealand. Mark is Chair of Training for the New Zealand Institute of Psychoanalytic Psychotherapy, and a member of the Psychoanalytic Psychotherapy Association of Australasia and the International Association of Relational Psychotherapy and Psychoanalysis. He has held the positions of Vice President of the South African Institute of Psychotherapy, Chairperson of the Cape Town Psychoanalytic Society, Psychology Professional Advisor for Pacific Health DHB, Committee Member of the NZ Institute of Counselling Psychology, and Head of Psychology at Auckland University of Technology. Contact details: mark.thorpe@aut.ac.nz . 